\title{
DIVISÃO \\ SIMBÓLICA \\ E AVALIAÇÃO \\ SOCIAL: \\ UMA ANÁLISE \\ DA LETRA \\ DA CANÇÃO \\ LATINOAMÉRICA ${ }^{1}$
}

\section{DIVISIÓN SIMBÓLICA Y EVALUACIÓN SOCIAL: UN ANÁLISIS DE LA LETRA DE LA CANCIÓN LATINOAMÉRICA}

\author{
SIMBOLIC DIVISION AND SOCIAL EVALUATION: AN ANALYSE OF THE SONG LYRICS \\ LATINOAMERICA
}

Nathan Bastos de Souza*

Universidade Federal de São Carlos

RESUMO: O objetivo deste artigo é estudar os sentidos da letra da canção "Latinoamérica”, da banda porto-riquenha Calle 13. A abordagem teórica foi desenvolvida com base nos estudos de Wacquant (2004) sobre o conceito de gueto, de Rama (2015) sobre a divisão simbólica e geográfica em torno de uma cidade das letras e nos estudos a respeito da avaliação social, com Medviédev (2012) e Volochínov (2013). Nossa análise desemboca em três caminhos: o primeiro, em que há a emergência de uma identidade de um continente em embate com uma alteridade opressora, o locutor se mistura corporalmente ao continente; o segundo caminho é introduzido no movimento de nossa análise como um enfrentamento direto ao interlocutor; e o terceiro eixo de nossa análise encaminha a construção de uma identidade coletiva. Por fim, "Latinoamérica" canta seu hino de resistência como garantia de um futuro de comunhão e luta conjunta latino-americana.

PALAVRAS-CHAVE: Gueto. Avaliação social. Estudos do discurso.

\footnotetext{
${ }^{1}$ Agradeço pela cuidadosa leitura que meu orientador, Prof. Valdemir Miotello, fez deste artigo em sua versão final.

* Doutorando em Linguística pela Universidade Federal de São Carlos (UFSCar). Este artigo foi realizado com apoio da Coordenação de Aperfeiçoamento de Pessoal de Nível Superior - Brasil (CAPES) - Código de Financiamento 00l. Email: nathanbastos600@gmail.com.
} 
RESUMEN: El objetivo de este artículo es estudiar los sentidos de la letra de la canción "Latinoamérica”, del grupo portorriqueño Calle 13. El abordaje teórico se desarrolló con base en los estudios de Wacquant (2004) sobre el concepto de gueto, de Rama (2015) respeto a la división simbólica y geográfica en torno a la ciudad letrada y en los estudios sobre la evaluación social con Medviédev (2012) y Volochínov (2013). Nuestro análisis llega a tres caminos: el primer de ellos, en que hay una emergencia de una identidad de un continente en embate con una alteridad opresora, el locutor se mezcla corporalmente al continente; el segundo camino se introduce en el movimiento de nuestro análisis como un enfrentamiento directo al interlocutor; y el tercer eje de nuestro análisis lleva a la construcción de una identidad colectiva. Al fin y al cabo, "Latinoamérica" canta su himno de resistencia como garantía de un futuro de comunión y lucha conjunta latinoamericana.

PALABRAS CLAVE: Gueto. Evaluación social. Estudios del discurso.

ABSTRACT: The aim of this paper is to study the meanings of the song lyrics "Latinoamérica", by the Puerto Rican band Calle 13. The theoretical approach was developed based on the studies of Wacquant (2004) about the concept of ghetto, by Rama (2015) about the simbolic and geographic division around the "cidade das letras" and the studies about the social evaluation, with Medviedev (2012) and Volochínov (2013). Our analysis results in three ways: the first, there is the emergency of an identity of a continent in conflict with an oppressive alterity, the speaker mixes bodily with the continent; the second way is introduced in the movement of our analysis as a direct confrontation to the interlocutor; and the third way of our analysis leads to the construction of a collective identity. Finally, "Latinoamérica" sings its ode to resistance as a guarantee of a future of Latin American communion and joint struggle.

KEYWORDS: Ghetto. Social evaluation. Discourse studies.

\title{
1 INTRODUÇÃO
}

\author{
Al principio, el saqueo y el otrocidio fueron ejecutados en nombre del Dios de los cielos. Ahora se cumplen en \\ nombre del dios del Progreso. Sin embargo, en esa identidad prohibida y despreciada fulguran todavía algunas \\ claves de otra América posible. \\ Eduardo Galeano
}

"Algunas claves de otra América posible", palavras de Galeano sobre a possibilidade de mudanças no horizonte da América Latina. Lugar de resistência, cinco séculos de proibição do arco-íris no céu americano - como ressalta o título do texto de Galeano - nos antecede. Em resposta a essas identidades proibidas e desprezadas, muitos lugares de resistência têm se constituído.

Nesse ínterim, trabalharemos neste artigo com a canção "Latinoamérica", da banca porto-riquenha Calle 13. Eleita canção do ano e melhor gravação de 2010 no Prêmio Grammy Latino, traz em sua letra - nosso objeto de estudos - a discussão sobre uma dessas chaves de uma América Latina possível diante do poder econômico, do Deus do Progresso. Desse modo, o objetivo que aventamos em nossa reflexão é estudar os sentidos da letra da canção "Latinoamérica". Para tanto, realizamos uma análise ancorada na reflexão de Wacquant (2004) e Rama (2015), que discutem, respectivamente, a noção de gueto e a assunção de uma cidade das letras como divisão simultaneamente geográfica e simbólica²; a reflexão sobre a linguagem encontra resguardo na noção de avaliação social desenvolvida por Medviédev (2012) e Volochínov (2013).

A análise que empreendemos permitiu a constituição de três momentos no desenrolar da letra da canção: o primeiro, em que se figura a construção de uma identidade do locutor que se mistura à forma do continente, torna-se corpo, e nesse movimento demarca uma alteridade de quem se quer distância; o segundo movimento, introduzido pelos refrãos da letra, mostra um enfrentamento

\footnotetext{
${ }^{2} \mathrm{O}$ conceito de simbólico é entendido como no interior da sociologia de Wacquant. Na psicanálise e na análise de discurso, sobretudo de vertente pechêutiana, o conceito é entendido diversamente. Na perspectiva sociológica, no entanto, o conceito de simbólico é entendido como de uma distribuição desigual de bens ou serviços que recebem valor socialmente. Tanto Wacquant quanto Rama desenvolvem uma discussão sobre a divisão simbólica que, respectivamente, o gueto e a cidade letrada produzem. Nessa esteira, os dois conceitos desses autores circunscrevem na estrutura física/geográfica a divisão simbólica entre os que podem/devem frequentar determinados espaços e os demais, que não podem. Pode interessar ao leitor aprofundar as discussões a respeito dessa concepção de simbólico com os trabalhos de Bourdieu (1999; 2013), que enfatizam o problema do capital simbólico como uma forma de hierarquização dos indivíduos.
} 
direto, com "dedo em riste", desse outro explorador; o terceiro e último movimento aparece especialmente nas últimas estrofes, em que esse locutor, que sempre conjugava os verbos na primeira pessoa do singular "yo soy", "yo tengo", se configura em uma identidade comunitária, passando a usar a primeira pessoa do plural para as conjugações verbais "vamos caminando", "vamos dibujando", etc.

Este artigo se constitui de três seções, as primeiras duas, depois da introdução, com caráter de revisão de literatura, e na terceira se desenvolve a análise. Na primeira seção, que trata do conceito de gueto como produto e instrumento de poder, revisamos o estudo de L.Wacquant sobre o gueto e cotejamos sua reflexão com A. Rama e a questão da cidade letrada como divisão geográfica e simbólica. Na segunda seção teórica, que tem ancoragem na teoria da linguagem, com base na noção de avaliação social, revisamos os textos de P. Medviedév e V. Volochínov a respeito da temática. A seção três é aquela em que analisamos a letra da canção objeto de estudo no quadro dessa reflexão sobre a divisão simbólica e sobre a avaliação social que reveste os recursos linguísticos. Ao final, apresentamos as considerações finais e a lista de referências bibliográficas.

\section{PRODUTO E INSTRUMENTO DE PODER: O GUETO COMO DIVISÃO GEOGRÁFICA E SIMBÓLICA}

O termo gueto, de acordo com Wacquant (2004, p. 157), é derivado do italiano e inicialmente se referia à "[...] consignação forçada de judeus a distritos especiais por parte de autoridades políticas e religiosas da cidade”. Na Europa medieval, os judeus agrupavamse em regiões dos centros urbanos e ali gestavam sua cultura e seus negócios, recebiam terras como doações e eram muito estimados pelo papel econômico que desempenhavam. Com as cruzadas, no período entre o século XIII e XVI, essa situação foi se invertendo. Tanto que, em 1516, o senado de Veneza decretou que os judeus fossem isolados em uma ilha, em um prédio com muros altos e janelas lacradas, protegendo o restante da população dessa convivência. A ilha era fortemente guardada em sua ponte por guardas, que permitiam a saída dos judeus apenas durante o dia para trabalhar na cidade; contudo, deveriam usar vestimentas que os diferenciassem dos demais cidadãos. Esse lugar era chamado, justamente, de ghetto nuovo.

Esse isolamento espacial dos judeus era a alternativa à expulsão, segundo o autor, já que a "[...] cidade-Estado [se beneficiava] economicamente da presença dos judeus [...] enquanto protegia seus residentes cristãos da contaminação por corpos concebidos como sujos e sensualmente perigosos, que carregavam sífilis e eram vetores de heresia, além de portar a mácula da usura e do dinheiro" (WACQUANT, 2004, p. 157).

A igreja católica na época igualava essas características à prostituição. Esse modelo de exclusão dos judeus se disseminou pelo Mediterrâneo, e os guetos por eles habitados, em resposta às diversas restrições, foram se organizando de tal modo que a vida social era voltada para dentro, "[...] de maneira que reforçava tanto a integração interna como a exclusão do externo" (WACQUANT, 2004, p.157).

Segundo Wacquant (2004, p. 157), a emergência da noção de gueto na Veneza de 1500 já permite observar os quatro elementos que constituem esse conceito sociológico, quais sejam,

[...] o estigma, o limite, o confinamento espacial e o encapsulamento institucional. O gueto é um meio sócioorganizacional que usa o espaço com o fim de conciliar dois objetivos antinômicos: maximizar os lucros materiais extraídos de um grupo visto como pervertido e perversor e minimizar o contato íntimo com seus membros, a fim de evitar a ameaça de corrosão simbólica e de contágio.

O gueto deve ser considerado, seguindo o pensamento de Wacquant (2004, p.159), como um produto e um instrumento de poder na medida em que é uma instituição de duas faces que "[...] serve a funções opostas para dois coletivos aos quais une em uma relação assimétrica de dependência”. A noção de gueto convém a interesses de classe social, funcionando como divisor entre aquilo que pode ou não estar dentro de uma redoma geográfica. De acordo com o crítico uruguaio Ángel Rama (2015), a separação geográfica é também uma divisão simbólica. Aqueles que frequentam o que Rama denominou de "anel do poder" - ele pensou no conjunto formado pelos "letrados" em torno do centro administrativo-político das cidades latino-americanas - costumam desenvolver o 
hábito de defender esse anel ${ }^{3}$. $\mathrm{O}$ anel se autodefende das investidas exteriores advindas da periferia do poder. Rama (2015, p. 53) afirma que as cidades - a geografia urbana, de uma maneira geral - se constituem de duas formas:

[...] a [rede] física, que o visitante comum percorre até perder-se na multiplicidade e fragmentação, e a [rede] simbólica, que a ordena e interpreta, ainda que somente para aqueles espíritos afins, capazes de ler como significações o que não são nada mais que significantes sensíveis para os demais, e, graças a essa leitura, reconstruir a ordem.

Essa rede simbólica é orquestrada e defendida pela divisão geográfica, ou seja, o simbólico encontra sua materialização na divisão física das cidades. Como veremos em nossa análise, a divisão física entre o que é América Latina e o que não é entrará e funcionará de maneira muito próxima à discussão sobre o gueto. A divisão simbólica se justifica na divisão espacial, como o gueto, a ideia de uma "cidade letrada" é também um cimento ideológico.

No contexto dessa dupla orientação da noção de gueto, porque concilia os objetivos antinômicos de dois grupos, circunscreve e controla em benefício do grupo dominante; já para o grupo dominado é "[...] recurso integrador e protetor [visto que] livra seus membros de um contato constante com os dominantes e permite colaboração e formação de uma comunidade dentro da esfera restrita de relações criada" (WACQUANT, 2004, p. 159). Duas formas de compreender um mesmo objeto simbólico: o gueto restringe a circulação daqueles que vivem do lado de dentro, preservando os habitantes do "anel do poder" (RAMA, 2015) da convivência; e uma segunda forma de compreender, que seria aquela oriunda da classe que vive no gueto, que se protege à sua forma e se integra de maneira a viver melhor naquelas condições de isolamento geográfico.

Nesse ínterim, é forçoso dizer que não se trata de uma relação pacífica, como se fosse aceito esse lugar predestinado por aqueles que nele vivem e como se fosse esperado por aqueles que dominam os meios de produção o isolamento da população mais pauperizada. Em outras palavras, os sentidos estão sempre em disputa e as divisões simbólicas são muito mais moventes que as cisões na geografia urbana. No gueto se materializam as formas de dominação étnico-raciais, uma vez que é responsável pela divisão no espaço da cidade. Mas, de forma muito mais cruel, é uma colossal "máquina de identidade coletiva” (WACQUANT, 2004, p. 161) que fortalece e elabora seus próprios limites a partir de duas formas que se completam:

Primeiramente, o gueto reafirma o limite entre a categoria marginalizada e a população que a circunda, uma vez que intensifica o abismo sócio-cultural entre elas: ele faz que seus residentes sejam objetiva e subjetivamente diferentes de outros residentes urbanos ao submetê-los a condições únicas, de maneira que os padrões de cognição e conduta sejam compreendidos como singulares, exóticos ou até aberrantes [...]. Em segundo lugar, o gueto é um motor de combustão cultural que derrete as divisões dentro do grupo confinado e alimenta o orgulho coletivo ao mesmo tempo em que fortifica o estigma que o assola. (WACQUANT, 2004, p. 161)

Cotejando a discussão de Rama (2015) sobre a necessidade do anel do poder instituído no centro das grandes cidades se autodefender, para defender os interesses da classe dominante, o gueto assume características próximas, uma vez que a ideia de comunidade tem um poder que age no nível objetivo - na divisão urbana, por exemplo - e no nível subjetivo - categorias de pertencimento e de demarcação da diferença. Dito de outro modo, na perspectiva em que o estigma que assola o grupo aumenta, o orgulho coletivo se retroalimenta, galvanizando os sentimentos de pertencimento, dividindo as mentalidades entre um "eu" e um "outro". O "eu" considerando a si mesmo como exótico em relação à diferença. Essa dupla face do gueto implica uma consequência perversa, como arma e como escudo, na medida em que "[...] sua completude institucional e autonomia minguam, seu papel protetor para o grupo subordinado diminui" (WACQUANT, 2004, p. 162), o restante desse jogo de forças é a função exclusivista do gueto. Dessa maneira, o medo do outro produzido pela máquina de identidade é a única arma com a qual se entrincheirar.

\footnotetext{
${ }^{3}$ Segundo Rama (2015, p. 43), no desenvolvimento das cidades latino-americanas, "No centro de toda cidade, conforme diferentes graus que alcançavam sua plenitude nas capitais vice-reinais, houve uma cidade letrada que compunha um anel protetor do poder e o executor de suas ordens: uma plêiade de religiosos, administradores, educadores, profissionais, escritores e múltiplos servidores intelectuais. Todos os que manejavam a pena estavam estreitamente associados às funções do poder". Essa organização da geografia urbana redundava no poder situado no ponto central - esse é o anel do poder - e os diversos estratos sociais distribuídos em sucessivos círculos concêntricos em direção à periferia do poder.
} 
Na seção seguinte apresentaremos os estudos de Medviédev (2012) e Volochínov (2013) sobre a noção de avaliação social.

\section{A DISCUSSÃO SOBRE AVALIAÇÃO SOCIAL}

O jogo das relações sociais é o cerne da reflexão do chamado Círculo de Bakhtin. Os autores desse grupo intelectual se inscrevem em lugares teóricos muito diferentes e sua reflexão vai da filosofia à teoria da literatura, passando por grandes contribuições para a reflexão sobre a linguagem. Nessa esteira, revisaremos como se dá a construção da noção de avaliação social e sua centralidade na teoria do enunciado concreto.

Medviédev (2012), inscrevendo-se em polêmica em relação à linguística de sua época ${ }^{4}$, demarca uma perspectiva de trabalho em que se levam em conta os enunciados concretos. Essa teoria, que encontra laços na reflexão mais ou menos contemporânea desenvolvida no Círculo, e a posteriori pelo próprio Bakhtin, parte do pressuposto segundo o qual a palavra é viva. Nesse sentido, a avaliação social "[...] está presente em cada palavra viva, já que a palavra faz parte de um enunciado concreto e singular" (MEDVIÉDEV, 2012, p. 183). Nas formas da língua, abstraídos “os aspectos da vida do discurso" (BAKHTIN, 2013, p. 207), encontra-se a língua abstrata de que tratavam os linguistas, conforme Medviédev (2012). A palavra isolada de sua ocorrência em discurso é mortificada, não apresenta, portanto, valor social.

O enunciado concreto se caracteriza por ser um ato social; por uma parte é "conjunto material peculiar" e, por outra, é "parte de uma realidade social" (MEDVIÉDEV, 2012, p. 184). Nesse fragmento se encontra já o que seria mais tarde a formulação definitiva, e quem sabe a mais conhecida dos autores do Círculo, de gênero discursivo. Em Bakhtin (2011), essa definição aparece estabelecida como enunciados relativamente estáveis que variam conforme conteúdo temático, estilo e construção composicional. Medviédev (2012) considera que esse enunciado concreto organiza a comunicação, que exige resposta e já é resposta, e que é inseparável do acontecimento da comunicação. O enunciado emerge como um acontecimento na história dos discursos, porque sua realidade não é a de um "corpo físico, mas a de um fenômeno histórico". O autor continua: "Não apenas o sentido do enunciado possui um significado histórico e social, mas, também, o próprio fato de sua pronúncia e, em geral, de sua realização aqui e agora, em dadas circunstâncias, em dado momento histórico, nas condições de dada situação social” (MEDVIÉDEV, 2012, p. 183).

De acordo com Medviédev (2012, p. 83), o enunciado passa de uma realidade natural para uma categoria de realidade histórica, porque "[...] o enunciado já não é um corpo nem um processo físico, mas um acontecimento da história, mesmo que infinitamente pequeno". Desse ponto de vista, recorta um universo de outros enunciados anteriores aos quais faz coro - em concordância ou em dissenso - e que existe em função das respostas que prevê, ou seja, um enunciado é eco de um passado que atualiza em sua emergência e também prenhe de respostas, de projeções de futuro. A língua abstrata que é estudada pelos linguistas, na esteira de Medviédev (2012), é desprovida da valoração social, é, então, língua de dicionário, língua de gramática. Isso não quer dizer que estudar a linguagem viva é percebê-la como um reflexo do real. Os enunciados, por serem históricos, se inscrevem em um jogo entre o que é da ordem do material - o linguístico, o dito - e o que é da ordem de um imaterial, por assim dizer, um extraverbal.

Medviédev (2012, p. 185) assegura que o próprio sentido passa a fazer parte da história, uma vez que especificamente esse sentido e não outro se tornou "[...] um objeto de discussão aqui e agora, que é dele que estão falando e que falam justamente assim e não de outra forma, que precisamente esse sentido entrou no horizonte concreto dos que falam”, tudo isso determinado pelas condições históricas e sociais da situação de emergência dos dizeres. Se reduzirmos os enunciados aos aspectos puramente verbais - aquilo que se diz -, as formas gramaticais que trabalharmos e explicitarmos até a exaustão redundarão em "[...] sinais técnicos de um sentido apenas possível e que ainda não foi individualizado historicamente" (MEDVIÉDEV, 2012, p. 185). Se ignorarmos a situação a que respondem os enunciados e elegermos para a análise apenas as formas repetíveis da língua de que se constituem, ignoraremos

${ }^{4}$ Quando tratarmos da linguística, estaremos fazendo menção sempre à linguística conforme a leitura dos autores russos, que escreveram, como se sabe, no começo do século XX 
também o papel que a avaliação social desempenha na formulação dos discursos: a escolha das palavras, as construções frasais, os ditos e os silêncios, todo um arsenal linguajeiro a serviço dos objetivos discursivos. A avaliação social se caracteriza por ser:

[...] justamente essa atualidade histórica que reúne a presença singular de um enunciado com a abrangência e a plenitude do seu sentido, que individualiza e concretiza o sentido e compreende a presença sonora da palavra aqui e agora. Pois é essa avaliação social que atualiza o enunciado tanto no sentido da sua presença fatual quanto no do seu significado semântico. Ela determina a escolha do objeto, da palavra, da forma e a sua combinação individual nos limites do enunciado. Ela determina, ainda, a escolha do conteúdo e da forma, bem como a ligação entre eles. (MEDVIÉDEV, 2012, p. 185)

A avaliação social que os enunciados guardam, nesse sentido, é uma injunção no que se refere à forma mesma do enunciado e a como responde ao horizonte de sua época. Os enunciados, assim, se organizam discursivamente - isto é, aquilo que se diz ou não, como se diz, em qual tipo de linguagem - em função de que, de quem e de como respondem. Isso não quer dizer que o enunciado concreto reflete a situação extraverbal como um espelho reflete um objeto. Como afirma Volochínov (2013, p. 79), o enunciado apresenta um resumo valorativo no qual a importância está em entender que os participantes do acontecimento discursivo que é o enunciado estão sempre em uma situação de co-partícipes, porque “[...] conhecem, entendem e avaliam essa situação" em conjunto. Tampouco, importa frisar, essa é uma teoria do consenso, longe disso, é uma teoria do diálogo, que pode ser consensual ou conflitivo. Nessa esteira, a "[...] enunciação se apoia em sua relação real e material a um mesmo fragmento da existência, atribuindo a essa comunidade material uma expressão ideológica e um desenvolvimento ideológico posterior" (VOLOCHÍNOV, 2013, p. 79, grifos no original).

O fator extraverbal não interfere nos enunciados mecanicamente, pelo contrário, integra e completa seus sentidos, é constitutivo. O enunciado concreto em sua vida é entendido como pleno de sentido, compondo-se de duas partes: "1) de uma parte realizada verbalmente e 2) do subentendido [... $]^{5 "}$ (VOLOCHÍNOV, 2013, p. 79). Essa noção de subentendido não é uma questão que possa ser resolvida no âmbito de uma consciência individual, diz respeito à ideia de grupo social.: "[...] trata-se antes de tudo de uma unidade material do mundo, que forma parte do horizonte dos falantes [...] e da unidade das condições reais da vida, que geram a comunidade de valorações: o pertencimento dos falantes a uma mesma família, profissão, ou classe social, a algum grupo social, finalmente, a uma mesma época, posto que todos os falantes são contemporâneos" (VOLOCHÍNOV, 2013, p. 80).

A valoração social, destarte, é a contraparte dos valores puramente abstratos das formas linguísticas que conformam os enunciados. Nesse ínterim, os enunciados concretos possuem uma parte verbal (ou sonora, ou visual, ou sincrética, etc.) e uma parte subentendida, no sentido usado por Volochínov (2013). Esse subentendido, é forçoso explicar, é aquilo que não está dito e que ecoa ao fundo dos textos. Não que seja preciso atravessar as materialidades discursivas para auscultar esse silêncio significante que estaria localizado em um alhures, mas ele se encontra lá em germe e as análises devem ser capazes de colocar em contexto os dizeres e de explicitar ao menos minimamente o pano de fundo em que se projetam.

Para Medviédev (2012) inclusive a fisionomia histórica de cada enunciado é determinada pela avaliação social. O autor russo aprofunda essa discussão:

De fato, é impossível compreender um enunciado concreto sem conhecer sua atmosfera axiológica e sua orientação avaliativa no meio ideológico. Por aceitar um enunciado não significa capturar seu sentido geral como capturamos o sentido de uma "palavra do dicionário". Entender um enunciado significa entendê-lo no contexto da sua contemporaneidade e da nossa (caso elas coincidam). É necessário compreender o sentido no enunciado, o conteúdo do ato e a realidade histórica do ato em sua união concreta e interna. (MEDVIÉDEV, 2012, p. 185)

\footnotetext{
${ }^{5}$ O termo "subentendido" pode dar ensejo à ideia de que atravessaremos enunciados em busca de uma “verdade” além das interpretações ingênuas. É preciso também afirmar que se concebe o enunciado como uma construção opaca, ou seja, não transparente. Assim, com base nas evidências verbais, buscaremos aventar as lacunas, os vazios de interpretação, os "subentendidos", sempre na perspectiva de Volochínov (2013). Partindo desse esclarecimento, a tarefa de análise empreendida por nós é entender o enunciado em sua atualidade histórica (MEDVIÉDEV, 2012), como junção da singularidade de sua existência e da plenitude e abrangência de seu sentido.
} 
Um enunciado concreto deve ser avaliado em contraponto com seu contexto de emergência do qual a avaliação social adveio. Assim, aquilo que um enunciado "diz" guarda também espaços vazios e lugares de inscrição histórica de sentidos. Não obstante, o enunciado é inteiramente penetrado pela avaliação social, porque todos os seus aspectos - para retomar a expressão de Bakhtin (2011) sobre os gêneros discursivos, o conteúdo temático, o estilo e a construção composicional - são atravessados pelos sentidos que se quer comunicar. A entonação expressiva, por exemplo, é uma característica advinda da avaliação social que se faz do que é dito, portanto será sempre mais instável que a entonação sintática (diferença entre o que é da ordem do sistema e é imutável e o que é da ordem da comunicação discursiva, mutável). Os enunciados concretos se constituem da palavra que é retirada do caldo comunicativo da comunidade discursiva em que emerge, a despeito da palavra mortificada dos dicionários, passa de um enunciado a outro porque tomada na corrente viva que vai da história da sociedade à história da língua.

Medviédev (2012) insiste, ainda, na crítica à linguística, afirmando que a tarefa dessa disciplina se restringiria a explicar o motivo de duas palavras ficarem lado a lado nas orações. Segundo o autor, seria imprescindível chegar até a avaliação social e transformar “[...] uma das possibilidades gramaticais em um fato concreto da realidade discursiva” (MEDVIÉDEV, 2012, p. 188). O elemento avaliativo seria responsável por mediar a relação existente entre a língua - sistema de possibilidades - e sua realidade concreta. Essa interferência da avaliação social de um grupo na produção dos enunciados faz com que Medviédev (2012, p. 189) afirme que um enunciado é uma "intervenção discursiva histórica", porque é uma exigência de resposta introduzida na corrente comunicativa como resposta a um alhures, isto é, que responde a algo anterior e exige resposta ao futuro do diálogo.

Na próxima seção discutiremos a letra da canção "Latinoamérica”, discutindo a divisão simbólica que representa, e trabalhando com a noção de avaliação social, que nos ajuda a balizar a análise com base no enunciado concreto dessa canção.

\title{
4 UMA ANÁLISE DE “LATINOAMÉRICA”, DIVISÃO SIMBÓLICA E AVALIAÇ̃̃O SOCIAL
}

A letra da canção que analisaremos é de autoria do grupo porto-riquenho Calle 13 e foi cantada em parceria, quando de sua gravação, com um trio de cantoras latino-americanas representativas da região: Susana Baca, peruana e figura chave no folclore latinoamericano, responsável por reviver a música afroperuana; Totó la Momposina, importante cantora folclórica da região caribenha da Colômbia; e a cantora brasileira Maria Rita, que canta trechos em espanhol e em português ${ }^{6}$. Nossa análise recairá exclusivamente sobre aspectos verbais dessa canção, ou seja, trabalharemos exclusivamente com a letra de modo a discutir como a avaliação social aparece no texto verbal. A primeira questão que levantamos a partir da letra da canção é que se faz um jogo entre o que é verbalizado e o não dito. A seguir, apresentamos a primeira estrofe, que é bastante longa:

\author{
[Calle 13 ${ }^{7}$ ] \\ Soy \\ Soy lo que dejaron \\ Soy toda la sobra de lo que se robaron \\ Un pueblo escondido en la cima \\ Mi piel es de cuero, por eso aguanta cualquier clima \\ Soy una fábrica de humo \\ Mano de obra campesina para tu consumo \\ Frente de frío en el medio del verano \\ El amor en los tiempos del cólera, ¡mi hermano! \\ Soy el sol que nace y el día que muere \\ Con los mejores atardeceres
}

\footnotetext{
${ }^{6}$ A canção faz parte do álbum “Entren los que quieran”, lançado em 2010, e é considerada do gênero hip-hop/rap. Foi indicada para concorrer em dez categorias do prêmio Grammy Latino, das quais venceu como canção do ano e gravação do ano.

${ }^{7}$ As notações entre colchetes na letra da canção demarcam aquele que é o cantor responsável pelo trecho, elas anteciparão, sempre, a estrofe cantada por esse cantor. Vale ressaltar, todavia, que essas notações têm apenas um papel ilustrativo.
} 
Soy el desarrollo en carne viva

Un discurso político sin saliva

Las caras más bonitas que he conocido

Soy la fotografía de un desaparecido

La sangre dentro de tus venas

Soy un pedazo de tierra que vale la pena

Una canasta con frijoles, soy Maradona contra Inglaterra

Anotándote dos goles

Soy lo que sostiene mi bandera

La espina dorsal del planeta, es mi cordillera

Soy lo que me enseñó mi padre

El que no quiere a su patria, no quiere a su madre

Soy América Latina, un pueblo sin piernas, pero que camina

¡Oye!

Nessa estrofe de introdução da canção já temos, desde o primeiro verso, o uso de primeira pessoa do singular na conjugação verbal. No primeiro verso, aparece o verbo "ser" conjugado na primeira pessoa do singular, no presente do modo indicativo, "soy". Essa forma verbal aparece isolada do que podemos chamar "sintaxe da canção", porque não está inscrita em uma oração maior, portanto, deixa um vazio à interpretação. Os dois próximos versos instauram a diferença entre o locutor da canção "[yo] Soy" e os demais, é que o pronome ele(s), a terceira pessoa - retomo aqui a diferenciação de Benveniste (2005) - é não pessoa. Nesse sentido, o contraponto entre o "eu" e o "ele" é que a terceira pessoa é sempre o causador de um mal, "Soy lo que dejaron", "Soy toda la sobra de lo que se robaron" em que "eu" é sempre um resto de um furto coletivo, aparentemente muito maior e poderoso (os verbos "dejaron" e "se robaron" estão conjugados na terceira pessoa, um "eles" é responsável por essas ações e não se identifica quem seria).

Nessa primeira estrofe, o verbo "ser" aparece doze vezes conjugado na primeira pessoa do singular no presente do indicativo, ressalte-se a durabilidade que é imposta pelo uso desse verbo. Efeito dessa repetição e de seu uso na primeira estrofe da canção é uma demarcação de uma identidade frente a uma alteridade exploradora ${ }^{8}$. Interessante avaliar o contraponto entre os versos em que figura essa forma verbal e aqueles em que não aparece, como em "Un pueblo escondido en la cima", "Mano de obra campesina para tu consumo", "Frente de frío en el medio del verano". Nesses três versos, como em outros dessa primeira estrofe, poderia ser encaixado sintaticamente o mesmo verbo "soy", porque esses versos também marcam lugares de identidade em diferença a uma alteridade que não possui essas características. Essa união ao redor do estigma de povo explorado é o efeito da noção de gueto, como vimos, uma forma de "integração interna e exclusão do exterior" (WACQUANT, 2004, p. 157).

Essa possibilidade de explicitação gramatical que fizemos acima demarca a avaliação social que o locutor da canção faz ao escrever os versos, visto que o jogo entre identidade e alteridade que é central nessa canção explora a diferença entre um Norte explorador e um Sul oprimido. Como vimos na discussão teórica a respeito do conceito de gueto, ele funciona como um cimento ideológico e, sendo assim, produz uma rede simbólica ancorada em uma rede física, para usar a terminologia de Rama (2015). Essa produção de uma integração interna e de uma exclusão do exterior faz, por exemplo, a escolha de cantoras de três países representativos na América Latina. Essa ideia de união continental surge, então, como "motor de combustão cultural” (WACQUANT, 2004, p. 161), um gueto que diminui as diferenças e aumenta as semelhanças em nome de sua lógica de resistência ao poder.

Também, no tocante a essa primeira estrofe, podemos considerar que o uso excessivo do verbo "ser" referindo-se ao próprio locutor é uma forma de misturar-se corporalmente com o continente que a canção glorifica. Isso se sustenta, por exemplo, se retomarmos os seguintes versos: "Soy una fábrica de humo", "Soy el sol que nace y el día que muere", "Soy el desarrollo en carne viva", "Soy la fotografía de un desaparecido", "Soy lo que sostiene mi bandera", "Soy lo que me enseñó mi padre", "Soy América Latina, un pueblo sin piernas, pero que camina”. Nesses versos temos um balanço entre características de força de trabalho humana/manual, da

${ }^{8}$ Nos estudos bakhtinianos, a relação entre identidade e alteridade é constitutiva e inseparável. Quando tratamos de identidade, aquilo que diz respeito ao "eu”, temos necessariamente de nos remeter a uma determinada alteridade, que se refere a "outros". A relação dos sujeitos é impreterivelmente uma relação entre alteridades, que se constituem no social, isto é, em interação. 
natureza e imagens de resistência. Exaltar a natureza e a força de trabalho para produzir com essas imagens uma memória da resistência é um lugar de diferença absoluto: o locutor afirma que é o trabalho, que é a natureza, que é suas forças em contraponto a um outro que não se diz no texto da canção, mas que, fundamentalmente, não possui essas propriedades. Nessa lógica, ao locutor afirmar "yo soy", ressalta a diferença que vê no outro, é como se respondesse "no eres asî", isso te falta.

Essa insistência no "ser" América Latina encontra um argumento importante, certamente, no livro "Las venas abiertas de Latinoamerica”, de Galeano (2013). Segundo esse autor, perdemos inclusive o direito de chamarmo-nos “americanos”. Esse é um efeito do encapsulamento institucional produzido pelo gueto, o poder econômico anima essas forças de resistência que insistem em dizer “Soy América Latina, un pueblo sin piernas, pero que camina”, em outras palavras, que caminha apesar de tudo, a despeito de qualquer força externa. À revelia da diferença, portanto, resiste. Desse modo, a força de resistir é uma forma de, contra tudo e contra todos, levantar-se diante das forças e das formas do poder econômico.

No plano metafórico da canção, podemos vislumbrar a feição de um corpo que se mistura ao continente, alguns índices linguísticos permitem interpretar essa valoração social que funciona como contexto em que inscrevem esse discurso a respeito da América Latina. Pela ordem que aparece na sintaxe da canção: a pele, as mãos, a carne viva, as caras, o sangue, a espinha dorsal, as pernas. A pele grossa do trabalhador que aguenta qualquer temperatura, as mãos do campesinato prontas para o trabalho, o desenvolvimento que se transforma em carne, o sangue dentro das próprias veias, a cordilheira dos Andes como a coluna vertebral do planeta, um povo que caminha mesmo na ausência de pernas, esse parece ser o resumo de uma grande obra sobre a história da exploração dos corpos na América Latina: tudo estaria a serviço do capital. Os corpos resistem, as forças de resistência constituem suas armas a partir daquilo que lhes é específico, daquilo que possuem. Se o trabalho é considerado um bem inestimável e a natureza um lugar de resguardo, essas são as formas de dizer, com as quais e pelas quais lutar.

"Ser" América Latina é assumir para si, para seu corpo, a resistência à força da exploração como uma força unificadora. A enunciação de "Ser" América Latina é apropriar-se do lugar de dizer do gueto, que implica um estigma, um limite, um confinamento espacial e um encapsulamento institucional. É encarnar no próprio corpo as formas de levantar-se contra a desigualdade instaurada para a população guetizada, é entender que as especificidades desse grupo oprimido são motivo de orgulho coletivo, capazes de organizar e galvanizar o levante contra os grupos hegemônicos. A existência do continente parece estar subordinada à existência do trabalho e das forças da natureza. Galeano (2013), nesse aspecto, afirma que a América Latina sempre é discursivizada a partir de uma imagem estereotipada provocada pela diferença da América do Norte, dos considerados “americanos", em que a América Latina não passaria de uma sub-América, uma América de segunda classe. É contra essa história da exploração alicerçada na suposta inferioridade que "Latinoamérica" canta sua resistência. Por fim, no verso "Soy el desarrollo en carne viva", o desenvolvimento econômico, essa coisa imaterial, se transforma em gente, gente latino-americana, ou seja, o desenvolvimento só existe porque há corpos a serem explorados, porque há carne para possuir, para se apossar.

Passemos agora a analisar os refrãos ${ }^{9}$, que darão um primeiro giro significativo no desenvolvimento de nossa análise.

A.

Totó La Momposina]

Tú no puedes comprar el viento

Tú no puedes comprar el sol

Tú no puedes comprar la lluvia

Tú no puedes comprar el calor

B. [María Rita]

Tú no puedes comprar las nubes

Tú no puedes comprar los colores

\footnotetext{
${ }^{9}$ Para efeito de análise e para evitar a repetição, preferimos nomear o primeiro refrão com a letra A e o segundo com a letra B. Na canção, eles se repetem duas vezes, no formato AB-AB. O primeiro par de refrãos a cargo da cantora colombiana Totó la Momposina e o segundo da brasileira Maria Rita; o segundo par de refrãos é realizado novamente por Totó la Momposina e o segundo por Susana Bacca.
} 
Tú no puedes comprar mi alegría

Tú no puedes comprar mis dolores

Sobre os refrãos, percebemos uma diferença significativa: aquilo que na primeira estrofe da canção era colocado em um espaço de não dito do enunciado - como vimos pela análise, a primeira estrofe deixa sempre em aberto quem seria esse outro explorador que acusa, mas não diz quem é - aqui aparece sendo francamente atacado e em uma posição de informalidade com o uso da segunda pessoa do singular com o pronome pessoal "tú". Os refrãos são constituídos por quatro versos em cada estrofe formada por quatro orações negativas. Os predicados todos são constituídos de sintagmas nominais com pares de determinante + substantivo. Todos os substantivos são elementos da natureza no primeiro refrão; elementos da natureza nos primeiros dois versos do segundo refrão e sentimentos nos segundos dois versos. Nesse sentido, se a natureza e os sentimentos não estão à venda, os corpos latino-americanos não são submissos, a resistência é a forma de existir diante do Norte explorador.

Colocar-se diante do outro em uma posição de informalidade, chamando-o de "tú", é uma forma de levantar-se que dá ensejo à discussão a respeito da avaliação social. Seria possível, pelas formas da língua, como sabemos, o uso de outras formas de interpelar o outro, que abrandassem esse efeito de embate. O efeito realizado pela proximidade/subjetividade introduzido pelo pronome "tú" desfaz essa ideia de que há um poder econômico superior que existe a despeito de qualquer resistência dos corpos, dos sujeitos. Efeito de subjetividade que aproxima aquele que diz daquele a quem se diz, assim, o outro explorador não está mais como um subentendido, como explica Volochínov (2013), mas como outro próximo a quem não se dá a importância do não dizer ou aquela do distanciamento. Desfaz-se, assim, o efeito de reverência/respeito não dito em que se contrapõem um "ser" e um "não ser" da primeira estrofe.

A repetição de "soy" é um contraponto - a avaliação social dá conta de explicar esse uso repetitivo - a "não ser", uma alteridade que é concebida como um "outro que não sou" (BUBNOVA, 2018), outro de quem se quer distância. Esse contraponto, como vimos, produz uma identidade coletiva (galvanizando a diferença entre o sujeito guetizado e o sujeito opressor), além de uma mistura corporal entre o locutor e o continente que, por esse motivo, atua às vezes como seu porta-voz. Medviédev (2012) afirma que os enunciados possuem uma inscrição na história na medida em que sua emergência, sua forma e sua realização aqui e agora respondem às condições da situação social. Nessa esteira, cada elemento de um enunciado é recortado do universo das possibilidades da língua em que se diz para, ao mesmo tempo, inscrever-se em um debate com a atualidade, antecipando as respostas possíveis que lhe sucederão. Como veremos adiante, o excesso do verbo "ser" para causar esse efeito de identidade servirá de fundamento para uma convocação de união - ênfase no "eu" com vistas a construir um "nós" - que conclui a canção, como veremos.

A estrofe seguinte é a segunda cantada pela banda Calle 13 na canção:

[Calle 13]

Tengo los lagos, tengo los ríos

Tengo mis dientes pa' cuando me sonrío

La nieve que maquilla mis montañas

Tengo el sol que me seca y la lluvia que me baña

Un desierto embriagado con peyote

Un trago de pulque para cantar con los coyotes

Todo lo que necesito, tengo a mis pulmones respirando azul clarito

La altura que sofoca

Soy las muelas de mi boca, mascando coca

El otoño con sus hojas desmayadas

Los versos escritos bajo la noche estrellada

Una viña repleta de uvas

Un cañaveral bajo el sol en Cuba

Soy el mar Caribe que vigila las casitas

Haciendo rituales de agua bendita 


\author{
El viento que peina mi cabello \\ Soy, todos los santos que cuelgan de mi cuello \\ El jugo de mi lucha no es artificial \\ Porque el abono de mi tierra es natural
}

Nessa estrofe aparece uma ênfase nos aspectos da natureza, e retorna a questão do trabalho e o uso frequente do verbo "tener". Quando da discussão da primeira estrofe, aventamos a possibilidade de que o locutor da canção se vale do "ser" na medida em que tem a ver com a construção de uma identidade, isso no nível da avaliação social. No tocante às formas da língua que se revestem da avaliação social, o verbo "ser", quando comparado ao verbo "tener", possui uma durabilidade maior em relação àquele. Essa discussão metalinguística se refere aos sentidos que se instauram nesse enunciado pelo uso de "ser" e "tener", já que a avaliação social que recai sobre as formas da língua impregna de sentido o enunciado, determinando "[...] a escolha [...] da palavra, da forma e a sua combinação individual nos limites do enunciado" (MEDVIÉDEV, 2012, p. 185). Nessa perspectiva, "tener" os lagos, os rios, as montanhas, o sol, as chuvas é algo mais passageiro em relação a alguns versos como "Soy, todos los santos que cuelgan de mi cuello". Desse prisma, os elementos da natureza que funcionam como objeto direto do verbo "tener" nessa estrofe se constituem como algo que pode ser perdido, na medida em que sua imaterialidade é movente, pode se tornar objeto de disputa econômica e deixar de pertencer à América Latina.

Parece ser possível afirmar, neste ponto de nossa discussão, que, quando o locutor afirma "yo soy", trata especificamente das características inatingíveis pela lógica do poder de estado no nível do simbólico. Isso se sustenta também nos refrãos, apesar de outras escolhas linguísticas. O verbo "ser" seria usado para designar aquilo que é da ordem do não negociável, daquilo que não se pode comprar, segundo os refrãos que acabamos de analisar acima. De tal modo, o que aparece nessa estrofe como objeto do verbo "tener" é o que pode, apesar dos protestos, apesar das resistências dos latino-americanos, ser vendido. Isso não implica, somente, a natureza como em "tengo los lagos, tengo los ríos", mas também em “tengo mis dientes pa’ cuando me sonrío", em que se poderia comprar, inclusive, o sorriso. A despeito do poder econômico, há a natureza (os lagos, os rios, as montanhas), há a diversão, há a poesia, há a espiritualidade. Tudo isso porque o trabalho vale a pena, como se vê nos versos "El jugo de mi lucha no es artificial", "Porque el abono de mi tierra es natural".

Com base nesse par de versos que concluem a estrofe, podemos ver a diferença entre o locutor e aquele de quem se distancia, aquele outro que rejeita em sua enunciação de resistência: resistir à opressão de um poder dominante com aquilo que é da ordem da natureza, lutar com as próprias mãos, trabalho bruto e manual diante de uma máquina de poder. As formas da resistência aparecem aqui formuladas como um orgulho coletivo, no sentido atribuído a essa expressão por Wacquant (2004), uma vez que, mesmo as características menores, como os dentes com que se sorri ou a altura que sufoca, são motivos de elevação do ideal de continente unido. Como veremos, esse motor de combustão cultural que o gueto proporciona aparecerá em nossa análise mais adiante como um episódio específico da história latino-americana. Nessa medida, o suor do trabalho dá orgulho como o resultado de uma luta de quinhentos anos contra as formas de opressão.

Depois dessa estrofe, se repetem os refrãos, cantados como A e B, por Totó la Monposina e Susana Bacca, uma vez cada. A análise desses versos foi feita acima. Para efeito de avanço na sintaxe da canção, manteremos apenas as notações desses dois refrãos no corpo do texto citado e passaremos à outra estrofe, em que Maria Rita canta, em português, uma versão alternativa dos refrãos; depois, em uma espécie de coro, as vozes das cantoras latino-americanas e da banca Calle 13 se misturam ao cantar os demais versos em espanhol dessa estrofe; os versos em português que se intercalam ao final da estrofe - exatamente o décimo segundo e o décimo quarto - são cantados pela voz de Maria Rita. A seguir apresentamos as notações de supressão dos refrãos em espanhol já analisados e a estrofe ora contextualizada: 
[Totó La Momposina]
[Refrão A].

[Susana Bacca]

[Refrão B].

[Maria Rita]

Não se pode comprar o vento

Não se pode comprar o sol

Não se pode comprar a chuva

Não se pode comprar o calor

Não se pode comprar as nuvens

Não se pode comprar as cores

Não se pode comprar minha'legria

Não se pode comprar minhas dores

No puedes comprar el sol

No puedes comprar la lluvia

(Vamos caminando) $)^{10}$

No riso e no amor

(Vamos caminando)

No pranto e na dor

(Vamos dibujando el camino)

No puedes comprar mi vida

(Vamos caminando)

La tierra no se vende

Para o caso dos primeiros oito versos dessa estrofe, como vimos, eles são uma versão alternativa dos refrãos A e B, como definimos anteriormente. Quando da descrição que fizemos dos refrãos em espanhol, notamos que havia uma diferença a partir do batimento da primeira estrofe da canção com os refrãos que acusam diretamente esse outro opressor que aparece como não dito na primeira estrofe. Como afirmamos, ao usar o pronome pessoal "tú" para se referir a esse outro, temos um tom de informalidade que redunda em reduzir a importância desse outro opressor, isto é, em reduzir o tom de reverência a esse outro e colocar-se em uma posição de enfrentamento direto, de "dedo em riste", por assim dizer. A versão em português que chamamos de alternativa faz com que esses sentidos deslizem, uma vez que não enfrenta esse outro cara a cara: os versos de um a oito cantados em português são a soma dos dois refrãos cantados anteriormente em espanhol, mas diferem na forma de tratamento, que naquele caso era direta, em segunda pessoa do singular; em português, usa-se a terceira pessoa, uma forma mais objetiva de referir-se ao outro. São oito orações negativas que usam também o verbo "comprar" e os mesmos objetos diretos como complemento nominal. O nono e o décimo versos são os mesmos que constituem o segundo e o terceiro versos do refrão que chamamos de A, acima.

Do décimo primeiro verso ao décimo oitavo há uma mudança significativa no tocante à enunciação do locutor. As pessoas do verbo vão deslizando à medida que a canção se distancia desse outro opressor que aparece nos refrãos em espanhol como "tú" e nesses versos como "ele". Esse deslizamento tem como efeito que o verso onze dessa estrofe apareça conjugado na primeira pessoa plural, ou seja, incluindo tanto o locutor quanto aqueles que são considerados seus ouvintes, copartícipes do ato, para usar a terminologia de Volochínov (2013). "Vamos caminando" é cantado em coro pelos cantores - além do uso de "nosotros" para a conjugação - e instaura, portanto, esse efeito de pluralização que vai acontecendo ao sabor do distanciamento desse outro que não se quer ser. $\mathrm{O}$ uso do gerúndio nessa construção com perífrase verbal empresta o sentido de movimento ao enunciado da canção, assim, a resistência é um caminho a ser percorrido e o locutor da canção prefere traçar esse caminho em companhia. "Vamos caminando" é repetido formalmente no décimo terceiro e no décimo sétimo versos dessa estrofe. Ajuda no efeito de movimento do enunciado o

${ }^{10}$ Os versos grafados entre parênteses são cantados por um coro, em um segundo plano da canção, superposto às vozes dos cantores. 
verso que aparece adiante, "Vamos dibujando el camino", que também se vale de gerúndio para dar a ideia de caminho a ser traçado; um caminho, portanto, plural.

Essa caminhada que se fará pode não ser tão suave, à medida que aconteça "No riso e no amor" ou "No pranto e na dor". Mas, o que se torna imperativo dizer é que a América Latina não está à venda, o que se pode afirmar a partir dos versos "No puedes comprar mi vida" e "La tierra no se vende". Se tomamos como um pressuposto que o locutor se mistura ao continente, como apresentamos anteriormente, a terra e a vida que não estão à venda são um só e mesmo lugar, a América Latina, transformada em corpo, em gente, em luta. A seguir, avançamos, já, para as duas estrofes finais da canção:

\section{[Calle 13]}

Trabajo bruto, pero con orgullo

Aquí se comparte, lo mío es tuyo

Este pueblo no se ahoga con marullo

Y si se derrumba, yo lo reconstruyo

Tampoco pestañeo cuando te miro

Para que te recuerde de mi apellido

La operación Cóndor invadiendo mi nido

Perdono, pero nunca olvido

¡Oye!

Nesses nove versos cantados pela Banda Calle 13 existe um destaque para o trabalho e para um balanço que traz a chave do movimento instaurado pela canção. O acontecimento da "Operación Cóndor" funciona aqui como um cimento ideológico, na medida em que foi uma situação que abarcou o continente como um todo e que causou graves danos à constituição das identidades latino-americanas, fraturadas ainda, no século XX, pelas independências recentes na maioria dos países. Conforme Calloni (1999), esse evento causou uma verdadeira rede de ditaduras no Cone Sul e na América Latina como um todo, fruto das articulações entre as agências de inteligência norte-americanas e os governos ditatoriais. Nesse sentido se revela, como um fecho à enunciação dessa canção, o inimigo jamais dito, os EUA, porque sendo a "[...] presença da palavra apenas o apêndice de uma outra presença" (MEDVIÉDEV, 2012, p. 190), a “presença dos subentendidos”, como afirma Volochínov (2013).

Tendo esse ponto de ancoragem - o evento da "Operación Cóndor" -, o estigma latino-americano de pobreza material se torna signo de resistência, signo de trabalho bruto, signo de luta. Quando o locutor afirma “Tampoco pestañeo cuando te miro”, temos a enunciação dessa posição de embate proposta pela canção desde o início, uma forma de enfrentamento que se reveste das formas de dizer disponíveis para atacar essa alteridade opressora e que se quer onipotente. Ao dizer que enfrenta o outro sem piscar os olhos, encara esse olhar do outro cara a cara e conclui: "Para que te recuerde de mi apellido", esse segundo verso retoma a memória dos desaparecidos das ditaduras que, patrocinadas pelos EUA, dizimaram os considerados "criminosos políticos". Os dois penúltimos versos concluem esse ataque ao outro invasor, como se vê em "La operación Cóndor invadiendo mi nido", ao que se responde "Perdono, pero nunca olvido". Essa canção, portanto, relembra a atualidade histórica do enunciado - como Medviédev (2012) -, responsável por reunir a presença singular do dito com a abrangência e plenitude de seu(s) sentido(s). Assim, essa canção aparece como uma retomada de episódios anteriores e contemporâneos.

O enunciado concreto resgata em sua temporalidade um alhures a que responde e ataca, nesse caso, e projeta um futuro em que convida a caminharmos juntos como latino-americanos e rechaçarmos também juntos esse outro opressor e detentor do poder de morte. Para finalizarmos, essa última estrofe merece ficar como uma palavra última a respeito desse contexto no qual se insere a canção, que se torna o pano de fundo das relações por nós analisadas, muitas delas subentendidas no todo do enunciado e na relação dele com o exterior, isto é, do enunciado com sua emergência histórica.

Vamos caminando

Aquí se respira lucha

Vamos caminando 


\author{
Yo canto porque se escucha \\ Vamos dibujando el camino \\ (Vozes de um só coração) \\ Vamos caminando \\ Aquí estamos de pie \\ ¡Que viva la América! \\ No puedes comprar mi vida.
}

\section{CONSIDERAÇÕES FINAIS}

A discussão que empreendemos neste artigo com o objetivo de estudar os sentidos da letra da canção "Latinoamérica" se desenvolveu sob os auspícios de reflexões teóricas que se complementaram no interior da análise: o conceito de gueto, ancorado em L. Wacquant, de cidade das letras em A. Rama, pensado como uma divisão na geografia urbana que produz uma divisão simbólica, e a teorização sobre a linguagem dos autores russos P. Medviédev e V. Volochínov, a avaliação social.

O conceito de gueto funciona atravessando a geografia urbana e chegando ao nível do simbólico dos sujeitos - rede física x rede simbólica (RAMA, 2015). Nessa medida, atua objetiva e subjetivamente sobre eles, é um cimento ideológico para o grupo. Quatro características do gueto são ressaltadas durante a revisão de literatura - o "estigma, o limite, o confinamento espacial e o encapsulamento institucional" (WACQUANT, 2004, p. 157). Em nossa análise, fomos discutindo a presença dessas características por meio dos índices linguísticos usados pelo locutor para se referir sobre o continente, sobre o outro opressor, sobre as características de sua luta de resistência diante do poder.

Sobre a avaliação social, conforme formulada por Medviédev (2012), percebemos na análise da letra que os recursos linguísticos são usados para efeitos ideológicos não necessariamente inerentes a eles. Em outras palavras, o uso de pronomes, o uso de verbos ou outros mecanismos linguísticos que analisamos no fio do discurso não apresentam um valor ideológico ${ }^{11}$ em si, anterior ao uso, mas são impregnados de sentido pelo enunciado concreto em que emergem. Nessa perspectiva, nossa análise buscou compreender esse enunciado concreto em sua "atmosfera axiológica e sua orientação avaliativa no meio ideológico" (MEDVIÉDEV, 2012, p. 185). Isso implica que os processos linguísticos, as retomadas, os deslocamentos do locutor em relação à própria enunciação da canção são ora mais objetivos, tratando o interlocutor na terceira pessoa, ora enfrentando-o diretamente, usando a segunda pessoa do singular, com uma posição que denominamos de "dedo em riste". O sentido desse enunciado, como analisado por nós, permite dividir didaticamente em três momentos a discussão:

1) Um primeiro momento, em que se dá a constituição dessa identidade sempre "proibida e menosprezada", para retomar os termos da epígrafe de Galeano, de um continente e de um locutor misturando-se, tornando-se corpo um do outro. Esse primeiro movimento, demarcado pela posição de emergência de um corpo que se levanta, que se revolta, que luta contra uma alteridade opressora, nesse momento não dita, tratada no bojo da enunciação como "ellos".

2) O segundo movimento aparece na letra da canção com a introdução de um enfrentamento direto ao interlocutor, chamando-o de "tú", essa discussão aparece nos dois refrãos constituídos por quatro orações negativas consecutivas, todas elas com base no mesmo verbo "comprar", com objetos diretos constituídos de elementos da natureza ou de sentimentos, o que demostra uma posição que nega o valor econômico das forças naturais e dos sentimentos, de modo a impossibilitar a exploração.

\footnotetext{
${ }^{11}$ A noção de ideologia, muito cara à reflexão do Círculo de Bakhtin, é central para pensar a relação entre linguagem e sociedade. As formas da língua se revestem de avaliação social, assim expressando a visão de determinados grupos sociais em que emergem os enunciados concretos. Nessa medida, a ideologia se materializa na linguagem por meio de signos. Indicamos ao leitor para complementar essa discussão, ademais das leituras do Círculo. Miotello (2013, p. 176), na perspectiva bakhtiniana, concebe como resumo que "[...] a ideologia é o sistema sempre atual de representação de sociedade e de mundo construído a partir das referências constituídas nas interações e nas trocas simbólicas desenvolvidas por determinados grupos sociais organizados”.
} 
3) O terceiro e último momento de nossa análise é reservado especialmente às últimas estrofes, na quais o locutor - lembremos que no primeiro momento os verbos que dizem do locutor são sempre conjugados em primeira pessoa - passa da primeira pessoa do singular, como em "yo soy", "yo tengo" à uma identidade mais plural, que une um "yo" e um "outros", constrói-se uma identidade comunitária com o uso da primeira pessoa do plural - "nosotros" - em versos como "vamos caminando", "vamos dibujando", etc.

Como emergência histórica, esse enunciado concreto da canção surge como resposta à alteridade opressora e vale-se, como frisamos, de um acontecimento unificador - a "Operación Cóndor" -, que tornou a América Latina lugar de uma rede de ditaduras militares que atuavam à sombra dos estados nacionais e foram responsáveis por dizimar, com justificativas "pretensamente" políticas, um grande número de pessoas. Resposta a um alhures, projeção das "chaves de uma outra América possível", "Latinoamérica" canta seu hino de resistência como garantia de um futuro compartilhado de luta e de união latino-americana.

\section{REFERÊNCIAS}

BAKHTIN, M. M. Os gêneros do discurso. In: BAKHTIN, M. M. Estética da Criação Verbal. Tradução de Paulo Bezerra. São Paulo: Martins Fontes, 2011.p. 261-307.

BAKHTIN, M. M. Problemas da poética de Dostoiévski. Tradução de Paulo Bezerra. São Paulo: Martins Fontes, 2013.

BENVENISTE, E. Problemas de linguística geral I. Tradução de Maria Glória Novak e Maria Luiza Neri. Campinas: Pontes, 2005.

BOURDIEU, P. Capital simbólico e classes sociais. Tradução de Fernando Pinheiro. Introdução e notas de Loïc Wacquant. Novos Estudos Cebrap, São Paulo, n. 96, p. 105-115, jul. 2013.

BOURDIEU, P. Os três estados do capital cultural. In: BOURDIEU, P. Escritos de Educação. Petrópolis: Vozes, 1999. p. 71 -79.

BUBNOVA, T. Para além da 'etnoficção’ ou quando o outro fala. Tradução de Nathan Bastos de Souza. In: SERODIO, L.; SOUZA, N. B. Saberes transgredientes. São Carlos: Pedro \& João Editores, 2018, p. 215-237.

CALLONI, S. Operación Cóndor: los años del lobo. Buenos Aires: Ediciones Continente, 1999

GALEANO, E. Las venas abiertas de América Latina. México DF: Ed. Siglo XXI, 2004.

GALEANO, E. Cinco siglos de prohibición del arcoíris en el cielo americano. In: GALEANO, E. Ser como ellos. México DF: Siglo Veintiuno, 1997. p. 17-33.

MEDVIÉDEV, P.N. O método formal nos estudos literários: introdução crítica a uma poética sociológica. Tradução de Sheila Grillo e Ekaterina Américo. São Paulo: Contexto, 2012.

MIOTELLO, V. Ideologia. In: BRAIT, B. (org.). Bakhtin: conceitos-chave. São Paulo: Editora Contexto, 2013.p. $167-176$

LATINOAMÉRICA. Intérprete: Calle 13. Compositores: R. PÉREZ; E. CABRA; R. ARCAUTE. In: ENTREN los que quieran. Intérprete: Calle 13. San Juan: Sony Music, 2010. 1 disco sonoro, faixa 7.

RAMA, A. A cidade letrada. Tradução de Emir Sader. São Paulo: Boitempo, 2015. 
VOLOCHÍNOV, V. N. A palavra na vida e a palavra na poesia. Introdução ao problema da poética sociológica. In: VOLOCHÍNOV, V. N. A construção da enunciação e outros ensaios. Tradução de João Wanderley Geraldi. São Carlos: Pedro e João Editores, 2013 , p. 71-101.

WACQUANT L. Que é gueto? Construindo um conceito sociológico. Revista de Sociologia e Política, v. 23, p. 155-164, 2004.

\section{(ㄷ) (1) $\circledast$}

Recebido em 16/05/20. Aceito em 26/06/2020. 